\title{
Safe and Effective Dosing of Over-The-Counter Melatonin use for Sleep Disturbances in Children with Autism: A Literature Review
}

\author{
Amelia Billingsley ${ }^{1}$ and Pilar Z Murphy ${ }^{2 *}$ \\ ${ }^{1}$ PharmD Candidate 2018, Samford University McWhorter School of Pharmacy, USA \\ ${ }^{2}$ Department of Pharmacy Practice, Samford University McWhorter School of Pharmacy, USA
}

Submission: August 25, 2018; Published: February 12, 2019

*Corresponding author: Pilar Z Murphy, PharmD, BCACP, Department of Pharmacy Practice, Samford University, 800 Lakeshore Drive, Birmingham, Alabama 35229, USA

\begin{abstract}
With the increasing prevalence of autism, it is important to identify if the over-the-counter (OTC) melatonin use for sleep disorders in autistic children is safe and effective. Since there are no FDA-approved medications for children with insomnia, this literature review aims to cast helpful insight for caregivers and physicians concerning the safe and effective use of OTC melatonin in autistic children for sleep disturbance relief. PubMed, International Pharmaceutical Abstracts (IPA), and Google Scholar were utilized in the search for studies for this literature review. Two randomized placebo-controlled crossover trials, one randomized placebo-controlled clinical trial, and two open-label trials were looked at for dosage strength, efficacy, and safety. From these trials, melatonin use seems effective and safe within the dosing ranges of $1 \mathrm{mg}$ to $10 \mathrm{mg}$. Titration may be needed in some children depending upon if they are a slow or fast metabolizer of melatonin. Improvements in sleep and in behavior were documented. Therefore, melatonin is seemingly safe and effective in helping autistic children with sleep disturbances by helping them go to sleep faster and stay asleep longer, thus giving them a better night's rest.
\end{abstract}

Keywords: Melatonin; Autism; Autism spectrum disorder; Sleep disturbances

Abbreviations: OTC: Over-The-Counter, CDC: Centers for Disease Control and Prevention, ASDs: Autism Spectrum Disorders, ASD: Autism Spectrum Disorder, AD: Autistic Disorder, AS: Asperger Syndrome, and PDD-NOS: Pervasive Developmental Disorder-Not Otherwise Specified, CSHQ: Children Sleep Habits Questionnaire

\section{Introduction}

With the increasing prevalence of autism [1], it is important to identify if the over-the-counter (OTC) melatonin use for sleep disorders in autistic children is safe and effective. The Centers for Disease Control and Prevention (CDC) reported that just from the year 2000 to 2012 there has been an increase in the prevalence of autism spectrum disorders (ASDs), from 1 out of every 150 children to 1 out of every 68 children, respectively [2]. According to Merriam-Webster's medical definition, autism is defined as "a developmental disorder that appears by age three and that is variable in expression but is recognized and diagnosed by impairment of the ability to form normal social relationships, by impairment of the ability to communicate with others, and by stereotyped behavior patterns especially as exhibited by a preoccupation with repetitive activities of restricted focus rather than with flexible and imaginative ones" [3]. Autism spectrum disorder (ASD) is defined by Merriam Webster as "any of a group of developmental disorders marked by impairments in the ability to communicate and interact socially and by the presence of repetitive behaviors or restricted interests" [4]. ASDs are comprised of three subgroups: autistic disorder (AD), Asperger syndrome (AS), and pervasive developmental disorder-not otherwise specified (PDD-NOS) [5]. ASDs are considered neurodevelopmental disorders largely stemming from genetic mutations, however the exact etiology is not currently known [5].

In autistic children, the circadian rhythm is disrupted due to low melatonin levels or due to unknown reasons. Behavioral agitation can result from the disruption and lack of sleep. It is reported that $44 \%$ to $83 \%$ of children with autism have difficulty with insomnia [1], as well as other sleep disturbances. Common difficulties with autistic children in their sleep habits are difficulties in settling down at bedtime with delays in sleep onset (sleep latency), in having a short sleep duration, and in experiencing frequent, extended night wakening's [6]. There are no FDA-approved medications for children with insomnia [1]. Since autistic children tend to have a high rate of insomnia and other sleep disturbances, an easy solution to help alleviate their sleep difficulties is needed. When non-autistic children have disrupted sleep for long periods of time, their mood, mental and physical health, coordination, memory, attention span, and 
rate of learning decline [7]. Those same declines are also seen in autistic children suffering from chronic sleep disturbances [8-10]. Since melatonin use in non-autistic children has proven effective for sleep difficulties, it could be a possibility for autistic children as well. This literature review aims to cast helpful insight for caregivers and physicians concerning the safe and effective use of over-the-counter melatonin in autistic children for sleep disturbance relief.

Melatonin (N-acetyl-5-methoxytryptamine) is a natural neurohormone that can cross membrane barriers easily and that affects the regulation of the circadian sleep-wake rhythm within the body [7]. Due to its ease of crossing membrane barriers, melatonin can inhibit neuronal excitability within the central nervous system [7]. Melatonin's plasmatic concentration "follows a circadian rhythm, with low levels during the day and high levels at night" [11]. Once night falls, melatonin levels increase rapidly then peak in the middle of the night; by dawn, the levels have decreased to lower concentrations [6]. Melatonin is synthesized from L-tryptophan through several metabolic intermediates, one of which is serotonin [12]. "[Endogenous] melatonin is of interest in autism spectrum disorder (ASD) due to its apparent role in neurodevelopment and reports of sleepwake rhythm disturbances in individuals with autism. More specifically, reduced total sleep and longer sleep latency as well as nocturnal and early morning awakenings, are often reported for individuals with ASD" [11].

One researcher hypothesized that a genetic mutation within the melatonin synthesis pathway could cause low melatonin and high serotonin levels in autistic individuals; therefore, this decrease in melatonin could cause abnormal sleep/wake cycles in individuals with ASD [13]. Thus, using exogenous melatonin therapy could be beneficial to correct the abnormality. Overthe-counter melatonin is often used for sleep disturbances in children without autism due to its low side effects, budget friendly cost, ease to locate, and relative effectiveness [12]. Several small studies have been conducted and have reported findings of positive relief in sleep disturbances in autistic children while taking melatonin. However, there is a wide range of dosage strengths being used. This literature review aims to compare the findings of the studies found and clearly show the doses of melatonin that are safe and effective for children with ASD.

\section{Methods}

For this literature review, PubMed, International Pharmaceutical Abstracts (IPA), Google Scholar, and Samford University Library Online were used to search for and obtain articles for this research. For this review, studies published in English within the time frame of January 2000 to August 2017 were searched. Medical Subject Heading (MeSH) terms used were "melatonin," "children sleep," "autism," and "autism spectrum disorder." The IPA basic search term used was "melatonin use in autism sleep disorders." Filters used in the search were
"English," "humans," and "clinical trial." The filter "clinical trial" had to be discontinued due to low volume of studies. Six studies were originally revealed; however, one of them was discarded due to only one autistic child being enrolled in the study. Studies considered were only for children who were autistic and had sleep disturbances. No Institutional Review Board (IRB) was needed.

\section{Results}

Garstang et al. [6] conducted a randomized, placebocontrolled, crossover trial that consisted of eleven autistic children ranging from 4 to 16 years old with significant sleep problems (identified as sleep latency of one or more hours, four or more nights a week, or night awakenings requiring attention by caregivers at least four nights a week, both causing distress to child and/or caregiver) [6]. The trial used $5 \mathrm{mg}$ of immediaterelease melatonin verse placebo. Each child took each medication for four weeks with a one week washout period between each treatment period [6]. The primary end points studied were sleep latency, number of nights wakening's, and total sleep time. The mean and 95\% confidence intervals (CI) were calculated for these three end points. Seven of the eleven children completed the trial; however, none of the children dropped out because of adverse effects. There was a drug recall due to the finding of some of the placebo capsules being empty, which caused two of the eleven children to drop out. Two other children dropped out for other reasons not related to the study. Results showed that sleep latency decreased with melatonin over placebo and baseline [1.06hr (95\% CI 0.98-1.13), 1.91hr (95\% CI 1.78-2.03), 2.60hr (95\% CI 2.28-2.93), respectively] [6].

Night wakening's were decreased with melatonin over placebo and baseline [0.08 (95\% CI 0.04-0.12), 0.26 (95\% CI 0.20-0.34), 0.35 (95\% CI 0.18-0.53), respectively] [6]. Total sleep duration increased with melatonin over placebo and baseline [9.84hr (95\% CI 9.68-9.99), 8.75hr (95\% CI 8.56-8.98), 8.05hr (95\% CI 7.65-8.44), respectively] [6]. Parents reported that their child was "easier to manage" while taking melatonin; and, therefore, the parents requested to have their child continue taking melatonin after the study was completed [6]. Garstang and Wallis concluded that immediate-release melatonin given at $5 \mathrm{mg}$ reduced sleep latency and night wakening's, as well as increased total sleep time.

Wright et al. [8] conducted a randomized, double-blinded, crossover trial that consisted of twenty autistic children, ages 4 to 16 years old, who were not responsive to behavior management alone for sleep disturbances (excessive sleep latency, excessive night wakening's, and reduced total sleep duration) [8]. Sixteen of those children completed the study. None of the four children who withdrew did so due to adverse effects. The trial involved three months of placebo and three months of melatonin with a one month wash out period in between. The immediate-release melatonin dose was started at $2 \mathrm{mg}$ and could be increased by $2 \mathrm{mg}$ every three days by the parent, if needed, to reach 
"good sleep" (an improvement of 50\% or better according to information given in their study packet), up to a maximum dose of $10 \mathrm{mg}$ [8]. The primary endpoints studied were sleep latency, total sleep time, and number of nights wakening's.

The results of the study showed that there was a statistically significant decrease in sleep latency with melatonin use over baseline $(82.84 \mathrm{~min}$ vs $135.00 \mathrm{~min}$, respectively) and over placebo (124.79min) with a p-value of 0.004 for both [8]. The results also showed that melatonin use provided statistically significant longer sleep times over baseline and placebo $(9.27 \mathrm{hrs}$ vs $8.33 \mathrm{hrs}$ and $8.46 \mathrm{hrs}$, respectively) with a p-value of 0.002 [8]. However, with a p-value of 0.209 , there was no statistically significant difference in night wakening's among the two arms compared to placebo [8]. Of the sixteen children who completed the study, twelve ended up taking the maximum dose of $10 \mathrm{mg}$ on the placebo arm compared to only six children who reached $10 \mathrm{mg}$ on the melatonin arm [8]. The average dose of melatonin taken by the children on the melatonin arm was $7 \mathrm{mg}$.

Table 1: Summary of Studies.

\begin{tabular}{|c|c|c|c|c|c|}
\hline Study & $\begin{array}{c}\text { Number of } \\
\text { Participants }\end{array}$ & Age Range & $\begin{array}{l}\text { Inclusion/ Exclu- } \\
\text { sion Criteria }\end{array}$ & $\begin{array}{l}\text { Formulation and } \\
\text { Dose of Melatonin }\end{array}$ & Results \\
\hline $\begin{array}{l}\text { Garstang et al. [6] } \\
\text { Randomized pla- } \\
\text { cebo- controlled } \\
\text { crossover trial } 9 \\
\text { week trial }\end{array}$ & $\mathrm{n}=7$ completed & 4-16 years old & $\begin{array}{c}\text { Inclusion: diag- } \\
\text { nosed with ASD, } \\
\text { sleep difficulties } \\
\text { Exclusion: previous } \\
\text { melatonin use }\end{array}$ & $5 \mathrm{mg}$ oral capsules & $\begin{array}{c}\mathbf{9 5 \%} \text { CI } \\
\text { Baseline: } 2.28-2.93 \mathrm{hrs} \mathrm{sleep} \mathrm{latency;} \mathrm{0.18-} \\
\text { 0.53 night wakenings per night; } 7.65-8.44 \mathrm{hrs} \\
\text { total sleep } \\
\text { Placebo: } 1.78-2.03 \mathrm{hrs} \text { sleep latency; } 0.20- \\
\text { 0.34 night wakenings per night; } 8.56-8.98 \mathrm{hrs} \\
\text { total sleep } \\
\text { Melatonin: } 0.98-1.13 \mathrm{hrs} \text { sleep latency; } \\
\text { 0.04-0.12 wakenings per night; } 9.68-9.99 \mathrm{hrs} \\
\text { total sleep }\end{array}$ \\
\hline $\begin{array}{l}\text { Wright et al. [11] } \\
\text { Randomized pla- } \\
\text { cebo- controlled } \\
\text { crossover trial } 7 \\
\text { month trial }\end{array}$ & $\begin{array}{c}\mathrm{n}=16 \text { com- } \\
\text { pleted }\end{array}$ & 4-16 years old & $\begin{array}{l}\text { Inclusion: diag- } \\
\text { nosed with ASD } \\
\text { with serious sleep } \\
\text { problems } \\
\text { Exclusion: previ- } \\
\text { ous/current use of } \\
\text { melatonin, current } \\
\text { psychotropic } \\
\text { medicine, and other } \\
\text { developmental/neu- } \\
\text { rological disorders }\end{array}$ & $\begin{array}{l}2 \mathrm{mg} \text { oral capsules } \\
\text { then increased by } \\
2 \mathrm{mg} \text { every } 3 \text { days if } \\
\text { needed up to } 10 \mathrm{mg} \\
\max \end{array}$ & $\begin{array}{c}\text { Baseline: } 135.0 \text { mins sleep latency; } 0.5 \text { night } \\
\text { wakings; } 8.33 \text { hrs total sleep } \\
\text { Placebo: } 124.79 \text { mins sleep latency; } 0.58 \\
\text { night wakenings; } 8.46 \text { hrs total sleep } \\
\text { Melatonin: } 82.84 \text { mins sleep latency; } 0.43 \\
\text { night wakenings; } 9.27 \text { hrs total sleep } \\
\text { Test statistics (DF), p-value of Melatonin } \\
\text { vs Placebo: t (15) =3.394, p=0.004 } \\
\text { sleep latency (mins) } \\
\text { t (15) }=1.313 \text {, p=0.209 } \\
\text { night wakenings } \\
\text { t (15) =3.75, p=0.002 } \\
\text { total sleep (mins) }\end{array}$ \\
\hline $\begin{array}{l}\text { Cortesi et al. [12] } \\
\text { Randomized pla- } \\
\text { cebo- controlled } \\
\text { clinical trial } 12 \\
\text { week trial }\end{array}$ & $\begin{array}{l}n=134 \text { complet- } \\
\text { ed }\end{array}$ & 4-10 years old & $\begin{array}{l}\text { Inclusion: diag- } \\
\text { nosed with ASD, } \\
\text { mixed sleep onset } \\
\text { and maintenance } \\
\text { insomnia } \\
\text { Exclusion: obesity, } \\
\text { breathing distur- } \\
\text { bances during } \\
\text { sleep, periodic } \\
\text { limb movement } \\
\text { disorders, children } \\
\text { with psychotherapy } \\
\text { or other behavioral } \\
\text { interventions, and } \\
\text { concurrent medica- } \\
\text { tions for less than } 6 \\
\text { months }\end{array}$ & $\begin{array}{l}\text { 3mg controlled-re- } \\
\text { lease capsules }\end{array}$ & $\begin{array}{l}\text { Baseline: CSHQ score } 2.88 \text { for sleep latency } \\
\text { for combination; CSHQ score } 2.90 \text { for sleep } \\
\text { latency for placebo; CSHQ score } 2.85 \text { for } \\
\text { sleep latency for melatonin; CSHQ score } \\
7.61 \text { night wakenings for combination; CSHQ } \\
\text { score } 7.76 \text { night wakenings for placebo; } \\
\text { CSHQ score } 7.67 \text { night wakenings for mela- } \\
\text { tonin; CSHQ score 7.34 for total sleep dura- } \\
\text { tion for combination; CSHQ score } 6.46 \text { for } \\
\text { total sleep duration for placebo; CSHQ score } \\
\text { 7.17 for total sleep duration for melatonin } \\
\text { 12-Week: CSHQ score } 1.69 \text { for sleep latency } \\
\text { for combination; CSHQ score } 2.93 \text { for sleep } \\
\text { latency for placebo; CSHQ score } 2.10 \text { for } \\
\text { sleep latency for melatonin; CSHQ score } \\
4.42 \text { night wakenings for combination; CSHQ } \\
\text { score } 7.86 \text { night wakenings for placebo; } \\
\text { CSHQ score } 5.03 \text { night wakenings for mela- } \\
\text { tonin; CSHQ score } 4.38 \text { for total sleep dura- } \\
\text { tion for combination; CSHQ score } 6.40 \text { for } \\
\text { total sleep duration for placebo; CSHQ score } \\
4.82 \text { for total sleep duration for melatonin } \\
\text { Baseline to } 12 \text {-week assessment p < } \mathbf{0 . 0 0 1} \\
\text { for sleep latency, total sleep duration, and } \\
\text { night wakenings }\end{array}$ \\
\hline
\end{tabular}




\begin{tabular}{|c|c|c|c|c|c|}
\hline $\begin{array}{l}\text { Giannotti et al. } \\
\text { [13] Open label } \\
\text { trial } \\
24 \text { month trial }\end{array}$ & $\begin{array}{c}\mathrm{n}=20 \mathrm{com}- \\
\text { pleted }\end{array}$ & $\begin{array}{l}\text { 2.6-9.1 years } \\
\text { old }\end{array}$ & $\begin{array}{l}\text { Inclusion: diag- } \\
\text { nosed with ASD, } \\
\text { sleep disorders } \\
\text { Exclusion: other } \\
\text { developmental/ } \\
\text { neurological dis- } \\
\text { orders, concurrent } \\
\text { medications less } \\
\text { than } 6 \text { months }\end{array}$ & $\begin{array}{l}\text { 3mg controlled-re- } \\
\text { lease capsules then if } \\
\text { needed } 1 \mathrm{mg} \text { imme- } \\
\text { diate-release capsule } \\
\text { (max } 4 \mathrm{mg} \text { in }<4 \mathrm{yr} \text { old } \\
\text { and max } 6 \mathrm{mg}>4 \mathrm{yr} \\
\text { old of immediate-re- } \\
\text { lease) }\end{array}$ & $\begin{array}{c}\text { Baseline: CSHQ score } 2.4 \text { for sleep latency; } \\
\text { CSHQ score } 6.5 \text { for night wakenings; CSHQ } \\
\text { score } 6.8 \text { for sleep duration } \\
\text { 6-Month: CSHQ score } 1.2 \text { for sleep latency; } \\
\text { CSHQ score } 3.6 \text { for night wakenings; CSHQ } \\
\text { score } 3.9 \text { for sleep duration } \\
\text { Rm-Ancova results: } \\
\text { F (4.76) }=30.4, \mathbf{p}<\mathbf{0 . 0 0 1} \text { for sleep latency } \\
\text { F }(4.76)=43.8, \mathbf{p}<\mathbf{0 . 0 0 1} \text { for night wakenings } \\
\text { F }(4.76)=48.9, \mathbf{p}<\mathbf{0 . 0 0 1} \text { for sleep duration }\end{array}$ \\
\hline $\begin{array}{c}\text { Malow et al. [15] } \\
\text { Open label trial } \\
14 \text { week trial }\end{array}$ & $\begin{array}{c}\mathrm{n}=24 \mathrm{com}- \\
\text { pleted }\end{array}$ & 4-9 years old & $\begin{array}{l}\text { Inclusion: diag- } \\
\text { nosed with ASD, } \\
\text { sleep onset delays } \\
\text { Exclusion: children } \\
\text { on psychotropic } \\
\text { medicines, other de- } \\
\text { velopmental/ neuro- } \\
\text { logical disorders }\end{array}$ & $\begin{array}{l}1 \mathrm{mg}(4 \mathrm{~mL}) \text { liquid } \\
\text { for } 3 \mathrm{wks} \text {; increased } \\
\text { to } 3 \mathrm{mg}(12 \mathrm{~mL}) \text { if } \\
\text { needed; increased to } \\
6 \mathrm{mg}(24 \mathrm{~mL}) \text { if needed }\end{array}$ & $\begin{array}{c}\text { Baseline: } 38.2 \text { mins for sleep latency; } \\
\text { End of Study: } 22.5 \text { mins for sleep latency } \\
\mathbf{p}<\mathbf{0 . 0 0 0 1} \text { for sleep latency }\end{array}$ \\
\hline
\end{tabular}

Wright et al summarized that whether taking lower dose or higher dose of melatonin, the results were similar, meaning that the children on the melatonin arm acquired significantly reduced sleep latency and acquired significantly increased total sleep time with no severe adverse effects at doses ranging from $2 \mathrm{mg}$ to $10 \mathrm{mg}$. Three side effects did present more frequently in the melatonin arm than in the placebo arm. Those side effects were diarrhea, reduced alertness/daytime drowsiness, and reduced appetite [8]. They were all mild in nature and did not cause any drop outs.

Cortesi et al. [9] conducted a double-blinded, randomized, placebo-controlled trial that investigated the differences of effectiveness among the treatment arms of melatonin monotherapy, melatonin plus cognitive behavioral therapy, cognitive behavioral therapy alone, and placebo. Melatonin monotherapy and melatonin combined with cognitive behavioral therapy showed the most effectiveness. One hundred and fortysix autistic children with sleep difficulties (defined as mixed sleep onset and maintenance insomnia) ages ranging from 4 to 10 years old participated in this trial; however, only one hundred and thirty-four were suitable for analysis due to drop outs from non-compliance, difficulties in administering medication, and lack of improvement [9]. The primary outcomes studies were the differences between the mean change from baseline to end of study between the different groups studied. The children assigned to the groups with cognitive behavioral therapy underwent four weekly meetings that lasted 50 minutes each along with their caregiver. Within these meetings, the therapist aimed to change any "dysfunctional beliefs and attitudes about sleep" that the child and/or caregiver had and to focus on educating the caregiver and child on proper sleep habits and behaviors [9]. Children assigned to the melatonin groups were given a $3 \mathrm{mg}$ dose of controlled-released melatonin administered around $9 \mathrm{pm}$ each night for 12 weeks with no dose adjustments permitted [9].

The results showed improvement in sleep latency, total sleep time, and number of nights wakening's. Results for sleep latency for the melatonin alone group and the combination group of melatonin and cognitive behavioral therapy showed a p-value of 0.001 with a $95 \%$ CI from baseline to the end of the 12 -week study [9]. Cortesi et al. [10] also stated that the results showed that the combination of melatonin and cognitive behavioral therapy proved the most effective with maintaining sleep (combination mean baseline to mean 12 -week endpoint 6.90 to $8.41 \mathrm{hrs}$ vs melatonin alone 6.84 to $8.02 \mathrm{hrs}$ vs cognitive behavioral therapy alone 6.80 to $7.42 \mathrm{hrs}$ vs placebo 6.88 to $6.94 \mathrm{hrs}$, respectively) and with reducing insomnia [12]. This study proved that having good sleep hygiene/sleep habits are beneficial to the child's wellbeing [12]. Cortesi et al. [10] also summarized from the findings of the study that melatonin alone was more effective than cognitive behavioral therapy alone with improving sleep onset, night wakening's, and sleep duration (Table 1) [9]. Furthermore, all treatment options proved more effective than placebo, and no adverse effects were reported. Cortesi et al. [10] believed that the three treatment options (combination of cognitive behavioral therapy and $3 \mathrm{mg}$ of melatonin, $3 \mathrm{mg}$ of melatonin alone, and cognitive behavioral therapy alone) could be recommended for help in autistic children with sleep disturbances.

Giannotti etal. [10] an open labelstudy of autistic children with sleep disorders being treated with melatonin, used controlledrelease melatonin as well as immediate-release melatonin. Twenty-nine children were enrolled in this two-year study with twenty of those children, ages ranging from 2.6 to 9.1 years old, completing it. The study compared the Children Sleep Habits Questionnaire (CSHQ) scores in order to gain understanding if the melatonin was having any effect upon the primary endpoints of sleep latency, sleep duration, and night wakening's, along with other endpoints of sleep anxiety, parasomnias, and daytime sleepiness (the latter three are not discussed in this review). A Children Sleep Habits Questionnaire is comprised of a "45item, parent-rated questionnaire that assesses the frequency of behaviors associated with common pediatric sleep difficulties" [14]. The questionnaire instructs parents to "rate the frequency with which their child has displayed various sleep behaviors during the previous week" [14]. These ratings are then combined to generate eight subscales that correspond to common sleep 
problems in children: bedtime resistance, sleep onset delay, sleep duration, sleep anxiety, night wakening's, parasomnias, sleep disordered breathing, and daytime sleepiness [14]. The lower the CSHQ score, the less disturbed the child's sleep was.

The first 6 months of Giannotti et al. [9] study used melatonin consistently, then all participants discontinued the melatonin for a month. If needed after the 7 months, the melatonin was readministered until the end of the 24 month study. All participants were evaluated at baseline, 1 month, 3 months, 6 months, 7 months (1 month after discontinuation), 12 months, and 24 months. To enroll, the autistic children had to be experiencing sleep onset insomnia, night wakening's, and/or early morning awakenings [10]. Each child was given $3 \mathrm{mg}$ of controlled-release melatonin taken 30-40 minutes before desired bedtime for 5 days; then, after the 5 days, the time of administration of the $3 \mathrm{mg}$ of melatonin was set at $8 \mathrm{pm}$ [10]. If needed, doses could be adjusted by the physician upward or downward at the followup clinics. Sometimes an additional $1 \mathrm{mg}$ fast-release melatonin was given at bedtime, if deemed necessary, to help with frequent night wakening's and/or persistent sleep onset delay. This fastrelease melatonin dose could be increased to $2 \mathrm{mg}$ if the child was waking up for more than 15 minutes during the night [13]. The fast-release dose was increased to a maximum of $4 \mathrm{mg}$ for children under 4 years old and a maximum of $6 \mathrm{mg}$ for children over 4 years old [10]. At follow-up visits, two of the children were given behavioral therapy to help with their bedtime routine (the caregiver was given instructions concerning better sleep routine habits for their child).

At the completion of the melatonin phase ( 6 months), the results from this study showed a statistically significant decrease in sleep onset delay (baseline score 2.4 vs 6 month score 1.2, p < 0.001 ) and in the number of night wakening's (baseline score 6.5 vs 6 month score 3.6, p < 0.001) with the use of melatonin [10]. Results also showed that sleep duration increased statistically significantly with the use of melatonin (baseline score 6.8 vs 6 month score 3.9, p < 0.001) [10]. No adverse effects were reported. For those who remained off the melatonin after the 1 month discontinuation (after 7 month mark), their CSHQ scores remained lower than baseline but higher than their 6 month score at their 12 month and 24 month evaluation [10]. Whereas, those who re-administered the melatonin after the 1 month discontinuation, their CSHQ score remained practically the same as their 6 month score at their 12 month and 24 month evaluation [10]. Giannotti et al concluded that the use of low dose melatonin ( $3 \mathrm{mg}$ of controlled-release $\pm 1 \mathrm{mg}$ of immediaterelease with a maximum of $4 \mathrm{mg}$ immediate-release for less than 4 year old and a maximum of $6 \mathrm{mg}$ immediate-release for 4 year old and older) was safe and effective in autistic children for sleep disorders. Giannotti et al. also deduced that it might be wise to "periodically withdraw [melatonin] to better evaluate its continuing positive effects" [10], believing that the child, with the help of melatonin, might have formed a good enough sleep habit that the child no longer needs the help of the melatonin to maintain a good night's sleep.

Malow et al. [15] an open label, dose-escalation study of melatonin use in children with autistic disorders that suffered from sleep onset delay, looked to find out the most effective and tolerable dose of melatonin that could be used to achieve an enough reduction in sleep onset delay. Forty-six children were enrolled but only twenty-four children, ages ranging from 3 years old to 9 years old, completed the study. The twenty-two children who did not complete the study either did not follow requirements or did not meet inclusion criteria. One child did withdraw due to seizures, which were deemed not associated with melatonin use [15].

This study used a one-week baseline and a two-week acclimation phase before the initiation of melatonin [15]. This study is different from the others in the sense that liquid melatonin was used. The children were given $1 \mathrm{mg}(4 \mathrm{~mL})$ of melatonin 30 minutes before bedtime for three weeks. If the child achieved a satisfactory response (falling asleep within 30 minutes of medication for 5 or more nights a week) [15], then the child remained on the $1 \mathrm{mg}$ dose until the end of the 14 week trial period. If there was not a satisfactory response after the first 3 weeks, then the child's dose was increased to $3 \mathrm{mg}(12 \mathrm{~mL})$ for three weeks. If a satisfactory response was achieved at the $3 \mathrm{mg}$ dose, then the child remained on the $3 \mathrm{mg}$ dose until the end of the 14 week trial period. If a satisfactory response was not achieved, then the dose was raised to $6 \mathrm{mg}(24 \mathrm{~mL})$ for three weeks. If the child still did not produce a satisfactory response, then the dose was increased to $9 \mathrm{mg}(36 \mathrm{~mL})$ and remained on until the end of the trial.

All twenty-four children gained a satisfactory response (falling asleep within 30 minutes of medication for 5 or more nights a week) with melatonin at some point during the trial [15]. No children reached the $9 \mathrm{mg}$ dose. Seven children reached a satisfactory response with the $1 \mathrm{mg}$ dose, fourteen children reached a satisfactory response with $3 \mathrm{mg}$, and three children needed $6 \mathrm{mg}$ to reach a satisfactory response [15]. Improvement in sleep latency was seen within the first week of the effective dose (whether $1 \mathrm{mg}, 3 \mathrm{mg}$, or $6 \mathrm{mg}$ ) [15]. Most of the children had no adverse effects; however, one child experienced some mild diarrhea [15]. The results from the study showed that there was a statistically significant reduction in sleep latency with melatonin use (38.2mins baseline sleep latency to $22.5 \mathrm{mins}$ at 14 weeks, $\mathrm{p}<0.0001$ ) [15]. Malow et al summarized that "most of the children responded favorably [sleep latency of 30 minutes or less on five or more nights during the week] to a $1 \mathrm{mg}$ or $3 \mathrm{mg}$ dose given 30 minutes before bedtime with an improvement in sleep latency" and that this improvement was "seen within the first week of dosing at the effective dose" [15].

From the studies that have been carried out in children with autism that experience sleep disturbances, most of these studies 
were very small in number and were short term. However, out of all the studies done, none of the candidates dropped out due to adverse events from melatonin. That is promising. Table 1 highlights each study, showing the number of children in the study, their age range, the inclusion and exclusion criteria, the dose of melatonin used, and the results from each study.

Three $[6,8,15]$ of the five studies used immediate-release melatonin, one [9] study used controlled-release melatonin only, and one [10] study used a combination of controlled-release and immediate-release melatonin. Three $[8,10,15]$ of the five studies allowed for titration, if needed. Furthermore, one study reported that all the children continued the melatonin even after the conclusion of the trial due to the effectiveness of the results [6] (Table 1).

\section{Discussion}

All these studies have very small population sizes ranging from 7 to 24 children, except for Cortesi et al. [9] with 134 children. It is difficult to form a true generalization for the larger population of autistic children, but a pattern can be seen from the data that is available. However, in the future, larger studies would be highly recommended to provide the most accurate data on dosage efficacy.

From these studies, it seems best to start with a low dose (1mg or $3 \mathrm{mg}$ controlled-release) of melatonin and titrate up until desired effectiveness is achieved. Some children could be slow metabolizers and others could be fast metabolizers of melatonin [7]. If the child is a slow metabolizer, a lower dose of melatonin would be warranted; whereas, with a fast metabolizer, a higher dose might be warranted. Some common side effects known to melatonin (such as cramps, diarrhea, daytime drowsiness, reduced appetite) were noted in some of the studies $[7,15]$. None of the participants in these five studies dropped out due to adverse events from the melatonin doses given, the highest being $10 \mathrm{mg}$. Both oral capsules and liquid formulations of melatonin were seemingly effective.

\section{Conclusion}

In conclusion, melatonin was seemingly safe and effective in helping autistic children with sleep disturbances by helping them go to sleep faster and stay asleep longer, thus giving them a better night's rest. This in turn helps with their overall wellbeing. As noted in the Cortesi et al. [9] study, melatonin, though effective by itself, should also be combined with consistent good sleep hygiene in order to see best results.

\section{Conflict of Interest}

There were no conflicts of interest and no financial support given/taken.

\section{References}

1. Brahm N, Erickson S, Stewart D (2017) Disorders associated with intellectual disabilities. In: Di Piro JT, Talbert RL, Yee GC, Matzke GR, Wells BG, Posey L (Eds.), Pharmacotherapy: A Pathophysiologic Approach, 10e New York, NY: McGraw Hill, USA.

2. CDC/ASD resource page (2017) Centers for Disease Control and Prevention website.

3. Autism (2017) Merriam-Webster website.

4. Autism spectrum disorder (2017) Merriam-Webster website

5. Johnson C, Myers S (2007) Identification and evaluation of children with autism spectrum disorders. Pediatrics 120(5): 1183-1215.

6. Garstang J, Wallis M (2006) Randomized controlled trial of melatonin for children with autistic spectrum disorders and sleep problems. Child Care Health Dev 32: 585-589.

7. Jan J, Freeman R (2004) Melatonin therapy for circadian rhythm sleep disorders in children with multiple disabilities: what have we learned in the last decade. Dev Med Child Neurol 46(11): 776-782.

8. Wright B, Sims D, Smart S, Alwazeer A, Alderson-Day B, et al. (2011) Melatonin versus placebo in children with autism spectrum conditions and severe sleep problems not amenable to behaviour management strategies: a randomised controlled crossover trial. J Autism Dev Disord 41(2): 175-178.

9. Cortesi F, Giannotti F, Sebastiani T, Panunzi S, Valente D (2012) Controlled-release melatonin, singly and combined with cognative behavioral therapy, for persistent insomnia in children with autism spectrum disorders: a randomized placebo-controlled trial. J Sleep Res 21(6): 700-709.

10. Giannotti F, Cortesi F, Cerquiglini A, Bernabei P (2006) An open-label study of controlled-release melatonin in treatment of sleep disorders in children with autism. J Autism Dev Disord 36(6): 741-752.

11. Tordjman S, Najjar I, Bellissant E, Anderson GM, Barburoth M, et al. (2013) Advances in the research of melatonin in autism spectrum disorders: literature review and new perspectives. Int J Mol Sci 14(10): 20508-20542.

12. Rossignol D, Frye R (2011) Melatonin in autism spectrum disorders: a systematic review and meta-analysis. Dev Med Child Neurol 53(9): 783-792.

13. Cortesi F, Giannotti F, Ivanenko A, Johnson K (2010) Sleep in children with autistic spectrum disorder. Sleep Med 11(7): 659-664.

14. Markovich A, Gendron M, Corkum P (2014) Validating the children's sleep habits questionnaire against polysomnography and actigraphy in school-aged children. Front Psychiatry 5: 188.

15. Malow B, Adkins KW, McGrew SG, Wang L, Goldman SE, et al. (2012) Melatonin for sleep in children with autism: a controlled trial examining dose, tolerability, and outcomes. J Autism Dev Discord 42(8): 17291737. 
(C) Commons Attribution 4.0 License BY DOI: 10.19080/OAJT.2019.03.555624

\section{Your next submission with Juniper Publishers will reach you the below assets}

- Quality Editorial service

- Swift Peer Review

- Reprints availability

- E-prints Service

- Manuscript Podcast for convenient understanding

- Global attainment for your research

- Manuscript accessibility in different formats

( Pdf, E-pub, Full Text, Audio)

- Unceasing customer service

Track the below URL for one-step submission https://juniperpublishers.com/online-submission.php 